\title{
Utopía, cultura crítica y sociedad industrial: una aproximación a la naturaleza subversiva del discurso sansimoniano
}

\author{
Francisco José MARTínEZ MeSA
}

Recibido: 16 de julio de 2013.

Aceptado: 2 de septiembre de 2013.

\section{RESUMEN}

Tras el término generalmente peyorativo de socialismo utópico, se dan cita una serie de pensadores y reformadores sociales comprometidos con los problemas del periodo posterior a 1789 , un tiempo atravesado por la inestabilidad y la emergencia de una nueva estructura de relaciones económicas. El caso de Saint-Simon y su escuela, el sansimonismo, constituye un claro exponente de uno de estos movimientos de corte renovador que acabaría sacudiendo y dinamizando la escena política y social de su época. En este trabajo analizaremos las dos dimensiones presentes en su proyecto: una doctrinal, más clásica y conocida, asociada al establecimiento de una futura sociedad industrial en Francia; y una segunda, inspiradora de un discurso potencialmente crítico, más próximo a la realidad de los problemas y, en consecuencia, considerado más peligroso y amenazador para el orden imperante.

\section{PALABRAS CLAVE}

Francia, sansimonismo, teoría política, utopía, liberalismo, sociedad industrial.

\begin{abstract}
Under the generally pejorative term of Utopian socialism there can be found a number of thinkers and social reformers committed to the problems of the period after 1789 , marked by instability and the emergence of a new structure of economic relations. The case of Saint-Simon and his school, Saint-Simonism, constitutes a clear example of one of these innovative movements that shook up and invigorated the social and political scene of the time. In this paper we shall analyze the two dimensions present within Saint-Simon's project. The more classic and well known side of his work is doctrinal, associated with the establishment of a future industrial society in France. A second dimension inspired a potentially critical discourse that addressed the existing social problems and, consequently, was considered more dangerous and threatening to the prevailing order.
\end{abstract}




\section{KEYWORDS}

France, Saint-Simonism, political theory, liberalism, utopianism, industrial society.

\section{Pensadores y HOMBRES DE ACCIÓN}

La aparición a comienzos del diecinueve en Francia de una serie de autores y propuestas intelectuales innovadoras supuso la consagración de una nueva manera de percibir la realidad. Y lo que es más importante, trazaría una línea de no retorno con respecto a épocas precedentes. Hasta entonces, solo unos pocos creían en la capacidad del ser humano para forjar su propia historia y, aun muchos menos, en que la sociedad fuera capaz de alcanzar la soberanía sobre sí misma.

Las pretensiones de muchos de estos pensadores contribuyeron a allanar un camino que amenazaba con conducir a la quiebra parcial y, en algunos casos, total del orden de cosas prevalente en su tiempo. La figura de Claude-Henri de Rouvroy, conde de Saint-Simon (1760-1825) constituye en buena medida un caso paradigmático de este grupo de pensadores y hombres de acción, comprometidos en la tarea de redefinir y reinterpretar las leyes que regían y configuraban la realidad social de su tiempo.

Cabe enmarcar la reflexión sansimoniana en un contexto lastrado aun por los efectos de la convulsión revolucionaria reciente y por toda una serie de traumatismos acumulados que solo podían invitar a un sentimiento de inseguridad permanente. La época estaba marcada por el Terror revolucionario añadido a las catástrofes del fin del reinado de Napoleón I, las exacciones fomentadas por las tropas de ocupación dirigidas por el Congreso de Viena y la ilegitimidad de los reyes restaurados, Luis XVIII (1755-1824) y Carlos X (1757-1836).

El discurso del sansimonismo ofrecía un cariz amenazador que, como habría sucedido a otros grupos de reformadores sociales, acabaría convirtiéndolo en algo subversivo y perturbador. Su doctrina podía contribuir no solo a abrir un espacio de esperanza; también podía preparar las condiciones para que el cambio se convirtiera en realidad. En un marco social y político muy diferente ya del vivido durante las primeras décadas del siglo (monarquía de Julio, 1830), el evidente potencial de su amenaza aumentaba. Una prueba de ello fue que quienes durante años habían sido sus más significados valedores y apoyos terminaron por renegar de aquellas tesis. A partir de entonces, estas quedaron confinadas en el imaginario y quimérico reino de las utopías. Y quienes hasta entonces habían sido sus compañeros de viaje fueron condenados a la más absoluta invisibilidad social. 
El verificar tal paradoja, recorriendo el tránsito iniciado por Saint-Simon a fines del dieciocho y culminado por su escuela en el primer tercio del siglo posterior, es el objeto de este trabajo ${ }^{1}$.

\section{LA CIENCIA POLÍTICA SANSIMONIANA}

El panorama abierto en el siglo dieciocho por la Ilustración y las Luces reveló las infinitas posibilidades de un porvenir de prosperidad y felicidad sustentado sobre la fe en el progreso irreversible e imparable del ser humano. Los extraordinarios avances experimentados en los últimos siglos invitaban a confirmar dicha creencia y tendían a asociarse con la creciente esfera de autonomía conquistada por el individuo frente a las tutelas y principios de autoridad de origen trascendente.

Tal horizonte de progreso y emancipación ilimitado no pudo evitar, sin embargo, la presencia de importantes escollos. De hecho, ya durante la Revolución francesa se hizo evidente la enorme complejidad de aquel movimiento universal, que no resultaba ser ni tan lineal ni tan progresivo como habían imaginado en su momento pensadores como Jacques Turgot (1727-1781) o Nicolas de Condorcet (1743-1794)2.

El escenario posrevolucionario francés tampoco favoreció las cosas. De hecho, dificultó la tarea ya de por si ardua, dada la magnitud de los retos planteados, tan ambiciosos a nivel nacional —el papel a desempeñar por la patria de la libertad a la hora de propagar el progreso al resto del género humano-, como desde un plano más amplio, universal - la racionalidad y moralización de la totalidad de las acciones y comportamientos emprendidos por la Humanidad-.

Imbuidos de aquella vocación científica inspirada en las Luces, filósofos, políticos y moralistas de aquel país se sirvieron de cuantos instrumentos tuvieron a su alcance para desentrañar los mecanismos que determinaban el proceder de sus semejantes ${ }^{3}$. Para esta tarea se sirvieron del concurso de las ciencias experimentales convencidos de que los resultados obtenidos — expresados luego en

\footnotetext{
${ }^{1}$ Esta investigación culmina una serie de estudios previos en los que he tratado de ofrecer una lectura novedosa del legado de Saint-Simon: Francisco MarTínez MESA, “¿Cosmopolitismo o nacionalismo? Apuntes para una reinterpretación del discurso internacionalista sansimoniano: Saint-Simon": Foro Interno, n. ${ }^{\circ} 2$ (2002), pp. 73-96; y, del mismo autor, "Entre la utopía y la necesidad: una reflexión sobre el cosmopolitismo sansimoniano": Revista de Estudios politicos, n. ${ }^{\circ} 147$ (2010), pp. 71-102.

${ }^{2}$ Frank E. MAnuel, The Prophets of Paris, Harvard University Press, Cambridge, 1962, passim.

${ }^{3}$ Philipp Blom, Gente peligrosa: el radicalismo olvidado de la Ilustración europea, Anagrama, Barcelona, 2012, passim.
} 
forma de leyes - permitirían controlar las acciones colectivas, como si un mayor conocimiento sobre aquel objeto de estudio implicara un mayor dominio sobre el mismo ${ }^{4}$.

Las ciencias, no obstante, cuentan con una importante dificultad de partida: su tendencia a la universalización y abstracción de los fenómenos concretos. Esto es algo que no siempre es posible adaptar a los procesos sociales. Sin embargo, y pese a ello, cada vez se ha tendido a recurrir más a sus procedimientos y métodos como soluciones de las que extraer orden y regularidad frente a la confusión y caos reinantes en determinados momentos. La Historia, por su parte, también adquirirá protagonismo en este sentido, colaborando en ofrecer las orientaciones y tendencias del porvenir.

El porvenir remite a la idea de una sociedad perfectamente unida y cohesionada en torno a sus obligaciones y aspiraciones; una imagen no siempre muy acorde, a decir verdad, con el escenario real. Este era el caso de la Francia de aquel entonces, sometida a un clima de inestabilidad política. El sombrío interludio del Directorio (1794-1799) no parecía invitar a un gran optimismo. Y, sin embargo, tal oscuro panorama no pudo eclipsar la pasión intelectual y la militante efervescencia científica de la época. Como señala Frank Manuel, la vieja estratificación social había explotado y la sociedad francesa aun no había creado otra $^{5}$. Los hombres no eran recibidos por los responsables del Directorio por su linaje sino por su intelecto. Sucedía así porque aquel Gobierno, confundido y desorganizado, no impuso una estructura formal sobre la sociedad, en estos momentos percibida como móvil. Tal percepción se reflejó igualmente en el mundo académico y científico: no había una rigidez jerárquica en las escuelas, sino una gran fluidez. La École Normale, la École Polytechnique o la de Médecine eran establecimientos educativos nuevos, no alterados por la caducidad y declive de los precedentes.

La voluntad reformadora de Saint-Simon surge de esa incertidumbre de vivir en un periodo de transición y crisis que no podía prolongarse por más tiempo. Sus raíces se remontaban más allá de la revolución de 1789, y afectaban no a un sector concreto de la sociedad sino al sistema en su conjunto, y más concretamente, a las bases y engranajes de la esencia misma de la sociedad.

El paréntesis político del Directorio se vio quebrado con el golpe de Estado de 18 Fructidor (4 de noviembre de 1797), posteriormente refrendado por el 18

${ }^{4}$ Michèle Riot-Sarcey, Le réel de l'utopie. Essai sur le politique au XIXe siècle, Albin Michel, Paris, 1998, p. 43.

${ }^{5}$ Frank E. Manuel, The New World of Henri Saint-Simon, Cambridge, Harvard University Press, 1956, passim. 
Brumario (9 de noviembre de 1799). Para algunos, como el propio Saint-Simon probablemente, el nuevo régimen no fue visto con malos ojos. Al igual que el despotismo ilustrado, este podía contribuir a poner en marcha las teorías sociales y filosóficas. Sin embargo, el antagonismo hacia Napoleón I (1769-1821) por parte del grupo de intelectuales conocido como los Idéologues —entre quienes se encontraban personalidades como Antoine Destutt de Tracy (1754-1836) o Pierre Jean Georges Cabanis (1757-1808) - pronto fue en aumento. Ellos habían esperado utilizar al corso como mascarón de proa para gobernar Francia. Pero cuando Napoleón empezó a rodearse de antiguos nobles y políticos ex jacobinos y emprendió iniciativas abiertamente opuestas al ideario de estos filósofos (por ejemplo, la firma del Concordato con la Iglesia Católica en 1801), su oposición se hizo más patente. A la vista estaba que Napoleón buscaba atraerse nuevos aliados. Ya no se trataba de proyectar la imagen de un régimen anárquico sino la de un gobierno monárquico, el Consulado, en el que los Idéologues ya no tenían cabida.

\section{El valor de la Historia y la Ciencia}

Aun cuando muchos proyectos dispusieran una transformación radical del marco de relaciones sociales existentes, lo cierto es que ninguna enarbolaba la bandera de una nueva revolución. En este sentido, cabe hablar de un amplio consenso a la hora de dar por cerrado el proceso revolucionario y excluirlo de todo discurso político. Un consenso, en cualquier caso, inducido desde una elite que si contemplaba algún cambio no era para dotar de una voz al pueblo, sino para encontrarle un nuevo lugar, un espacio claramente circunscrito dentro de un contexto material y espiritual más desarrollado ${ }^{6}$.

Las reglas sociales aun no estaban plenamente instauradas y las que parecían estarlo, tendían a ahondar la división entre el cuerpo de derechos individuales, excesivamente abstractos, y el cuadro de inestabilidad y conflictos de la realidad de su tiempo. En consecuencia, fueron emergiendo o recuperándose planteamientos que desde la razón o, si esta no bastaba, desde la religión y la moral, aspiraban a contribuir a la reconstrucción del vínculo social en el nuevo siglo.

En el caso de Saint-Simon, la Historia y la Ciencia adquirirían entonces plena naturaleza política al servicio de un proyecto de reordenación social acorde con las exigencias de los sectores sociales y políticos que habían salido victoriosos del proceso revolucionario. Aunque pueda parecer paradójico, la nueva consideración de la política como ciencia positiva — una disciplina exacta y evi-

\footnotetext{
${ }^{6}$ Riot-SARCEy, Le réel de l'utopie, p. 86.
} 
dente por sí misma - no deja de ser deudora del traumático episodio de la Revolución ${ }^{7}$. La acelerada e infructuosa sucesión de experiencias y vaivenes políticos puesta en marcha en 1789 había dejado clara la impotencia de la palanca política en una sociedad sumida en la desorientación y la anomia. Solo cuando el conjunto del cuerpo social asumiera plenamente sus aspiraciones y sus compromisos, podría reconsiderarse la función nuclear de lo político:

El siglo dieciocho no ha hecho sino destruir; y nosotros de ninguna manera continuaremos su obra: lo que nos proponemos, por el contrario, es echar los cimientos de una construcción nueva; y plantear y tratar en ella la cuestión de los intereses comunes, cuestión hasta ahora intacta; hacer que la política, la moral y la filosofía, en lugar de detenerse eternamente en contemplaciones ociosas y sin práctica, sean conducidas por fin a su verdadera ocupación, que no es otra que la de constituir la felicidad social, hacer, en una palabra, que la libertad termine de ser una abstracción, y la sociedad una ficción ${ }^{8}$.

En este sentido, el recelo de Saint-Simon mostrado en 1821 no es contra la política, sino contra el uso que se había hecho de ella hasta ese momento. Había sido utilizada al servicio de los más poderosos para reprimir los conflictos e imponer unilateralmente la estabilidad social. A su juicio, lo practicado hasta entonces no era política, porque nada tenía que ver con la ciencia o el conocimiento, sino más bien con la ignorancia y el antagonismo:

Es por el efecto de nuestra ignorancia política que estamos en guerra los unos con los otros, en lugar de combinar nuestras fuerzas para actuar sobre la naturaleza, a fin de obtener de manera más abundante los medios para satisfacer nuestras necesidades...Pocas luces llevan al error, muchas luces conducen a la verdad ${ }^{9}$.

${ }^{7}$ La revolución francesa marcó una divisoria, y prueba de ello es que a medida que transcurre el siglo diecinueve, resulta cada vez más difícil trazar la frontera entre imaginario y realidad, entre proyecto utópico y programa político. Yolène Dilas-Rocherieux, L'utopie ou la mémoire du futur. De Thomas More à Lenine. Le Rêve éternel d'une autre société, Robert Laffont, Paris, 2000, p. 46.

8 'Le XVIIIe siècle n'a fait que détruire; nous ne continuerons point son ouvrage: ce que nous entreprenons, au contraire, c'est de jeter les fondements d'une construction nouvelle; c'est de poser et de traiter en elle-même la question des intérêts communs, jusqu'ici laissée pour ainsi dire intacte; c'est de faire que la politique, la morale et la philosophie, au lieu de s'arrêter éternellement à des contemplations oiseuses et sans pratique, soient ramenées enfin à leur véritable occupation, qui est de constituer le bonheur social; c'est de faire, en un mot, que la liberté ne soit plus une abstraction, ni la société un roman". Claude Henri de SAINT-Simon, "Du Système industriel", en Oeuvres de Saint-Simon \& d'Enfantin (en adelante OSSE), Paris, 1865-78, vol. XXI, p. 6.

9 'C' autres, au lieu de combiner nos forces pour agir sur la nature, de manière à en obtenir plus abondamment 
La demolición del edificio del Antiguo Régimen auguraba un porvenir prometedor, pero siempre y cuando el nuevo orden fuera capaz de vertebrar la diversidad de aspiraciones y expectativas tan súbitamente liberadas. Restaurar la política tal y como se había entendido hasta entonces, como sinónimo de la arbitrariedad de los hombres ("la acción de gobernar es nula, o casi nula, en tanto significa acción de mandar"10), solo suponía poner puertas al mar. De lo que se trataba, por el contrario, era de desarrollar una sólida ingeniería social capaz de canalizar aquella totalidad de intereses y reorientarlos sobre la base de un compromiso colectivo común. Algo, en suma, a años luz de lo que la Restauración borbónica había venido ofreciendo desde 1814.

Este proyecto implicaba una nueva concepción del poder y de la autoridad. En efecto, en la medida en que la Historia revelaba, a juicio de Saint-Simon ${ }^{11}$, que en las sociedades avanzadas la evolución de la humanidad tendía a postergar la acción de gobernar a una posición subalterna, el problema de los poderes pasaba a ser contemplado como un problema de funciones ${ }^{12}$.

Ha llegado el momento en que los poderes van a verse obligados a ceder ante 'las capacidades' y los gobiernos solo se sostendrán mediante 'el examen'. Las funciones que tienen especialmente como objeto el mantenimiento del orden, ya no serán más clasificadas dentro de la nueva organización social sino dentro de su rango natural, es decir, como funciones subalternas y de policía, pues resulta evidente que solo pueden ser funciones principales mientras la asociación no tenga un fin; en el momento en que esta tenga cualquiera, aquellas devendrán secundarias ${ }^{13}$.

les moyens de satisfaire nos besoins...Peu de lumières mènent à l'erreur, plus de lumières conduisent à la vérité". Claude Henri de SAINT-SimOn, "Du Système industriel", en OSSE, vol. XXIII, p. 30

10 "L'action de gouverner est nulle, ou presque nulle, en tant que signifiant, action de commander". Claude Henri de SaInt-SimOn, "L'Organisateur" (Paris, 1818-1819), en OSSE, vol. XX, p.199.

${ }^{11}$ Claude Henri de SAINT SIMON, L'action de gouverner a du être, jusqu'à l'anéantissement, de l'esclavage, l'action prépondérante; aujourd'hui, et de plus en plus, elle ne doit plus être qu'une action subalterne. De la organisation sociale, fragmentos de una obra inédita recopilados en Opinions littéraires, philosophiques et industrielles (Paris, 1825), en OSSE, vol. XXXIX, pp. 114-116.

${ }^{12}$ Enrico VIDAL, Saint-Simon e la scienza politica, Giuffré, Milano, 1959, p. 37.

13 "Le temps est venu où les pouvoirs vont être forcés de céder aux "capacités", et où les gouvernements ne se soutiendront que par "l'examen". Les fonctions qui ont spécialement pour objet le maintien de l'ordre, ne seront donc plus classées, dans la nouvelle organisation sociale, que suivant leur rang naturel, c'est-à-dire, comme des fonctions subalternes et de police: car, il est évident qu'elles ne peuvent être fonctions principales qu'autant que l'association n'as pas de but; du moment qu'elle en a un quelconque, elles deviennent secondaires". SAINT-Simon, "L'Organisateur", en OSSE, vol. XX, pp. 201-202 y 224. 
En cualquier caso, todo avance quedaba inscrito dentro de una perspectiva general - luego asumida por los discípulos - en donde la ciencia y la industria eran valorados más en su condición de instrumentos catalizadores de la dinámica social — en tanto factores de transformación de las relaciones en la sociedadque por su aportación al conjunto concreto de conocimientos ${ }^{14}$.

La concepción de ciencia inicialmente adoptada por Saint-Simon, aquella que, heredada del siglo dieciocho, situaba al hombre como su principal protagonista, fue cambiando como consecuencia de las crecientes expectativas depositadas en las nuevas ciencias humanas. En este sentido, cuando el autor acabó afirmando "que la crisis social en la que los pueblos más iluminados del mundo están inmersos no habrá enteramente terminado hasta el momento en que la política sea tratada, cultivada y enseñada de la misma manera que la física, la química y la fisiología lo son hoy en día ${ }^{15}$ ", estaba contribuyendo a la configuración de un ideal de eficacia construido sobre una articulación de representaciones y prácticas cuyo objeto último era perfeccionar el funcionamiento de unos sistemas y unas organizaciones dadas ${ }^{16}$.

Inicialmente influido por hombres como Jean Burdin, miembro del grupo de los Idéologues y autor del importante Cours d'études médicales ou exposition de la structure de l'homme (1803) ${ }^{17}$, Saint-Simon se serviría de la fisiología, una disciplina, a su juicio, preeminente sobre el conjunto de ciencias humanas en general. Se trataba de una ciencia positiva que insistía en la interacción entre las propiedades morales y físicas, y al mismo tiempo afirmaba que el nivel de inteligencia de los organismos era proporcional al grado de perfección de sus estructuras ${ }^{18}$. Desde esta nueva perspectiva, el autor analizaría la evolución histórica de la especie humana mediante el examen de sus cuerpos sociales. Los consideraba dotados, como el resto de organismos vivos, de su correspondiente constitución y morfo-

${ }^{14}$ De hecho, pese a presentarse como adalides de la industria y los industriales, en sus obras hay pocas referencias a sus aplicaciones concretas. Antoine PICON, Les saint-simoniens. Raison, imaginaire et utopie, Belin, Paris, 2002, p. 20.

15 "[Q]ue la crise sociale dans laquelle les peuples les plus éclairés du monde sont engagés ne sera entièrement terminée qu'à l'époque où la politique sera traitée, cultivée, et enseignée de même que la physique, la chimie et la physiologie le sont aujourd'hui". Claude Henri de SAINTSimon, Le politique, Paris, 1819, p. III.

${ }^{16}$ Antoine Picon, "Towards a history of technological thought", en Robert Fox (ed). Technological Change. Methods and Themes in the History of Technology, Routledge, London, 1996, pp. 37-49.

${ }^{17}$ Para Saint-Simon, que financió la publicación de sus obras, Burdin condensaba en su ciencia los logros alcanzados por la anatomía de Vicq-d'Azur, la fisiología de Bichat, la psicología de Cabanis y la historia filosófica de Condorcet. MANUEL, The New World of Henry Saint-Simon, p. 130.

${ }^{18}$ Robert WOKLER, "Saint-Simon and the passage from political to social science", en Anthony Pagden (ed.), The Languages of Political Theory in Early-Modern Europe, Cambridge University Press, Cambridge, 1996, pp. 325-338. 
logía natural. En su análisis primaba la organización de las sociedades sobre los intereses particulares de los individuos.

La historia, en tanto disciplina que contemplaba el devenir de la existencia del hombre y extraía de él una serie de regularidades susceptibles de alcanzar la categoría de leyes, pasaba a convertirse en ciencia. En una ciencia cuya condición positiva derivaba de la constatación de esa permanente voluntad del ser humano de conquistar su emancipación ante las dificultades impuestas por el entorno hostil representado por la naturaleza.

\section{EL GOBIERNO DE LAS ELITES}

En una fase inicial, aproximadamente hasta 1816, Saint-Simon circunscribía la profunda transformación de la vida política y social al ámbito del saber, limitando la responsabilidad de hacer reformas a la elite científica ${ }^{19}$. Las convulsiones sociales eran atribuidas al desorden del saber o a la inexistencia de una sistematización de las ciencias. Sin embargo, a partir de esa fecha y con la publicación de L'Industrie (1816-1818), la crisis intelectual aparece como un aspecto más de un cambio histórico más general, que atañe al orden de las sociedades en su totalidad.

En este sentido, la exigencia de unidad requerida por el sistema iba a obligar a repensar el adecuado trazado de la sociedad futura ${ }^{20}$. La Industrie comprendía todas las actividades productivas, incluidas las desempeñadas por escritores, artistas o científicos. De este modo, emerge como la actividad colectiva de producción dominante en la sociedad:

La industria solo es un único y vasto cuerpo en donde la totalidad de sus miembros responden y son, por así decirlo, solidarios; el bien y el mal de cada uno afecta a los demás; solo hay un interés, una necesidad, una vida ${ }^{21}$.

La actividad colectiva estaría dominada por la cooperación espontánea y el rechazo a toda autoridad arbitraria. Frente al papel tradicionalmente concedido a

${ }^{19}$ Lucian BoIA, La Mythologie scientifique du communisme, Belles Lettres, Paris, 2000, pp. 32-34; Langdon Winner, Autonomous Technology. Technics-out-of-Control as a Theme in Political Thought, MIT Press, London, 1977, p. 140.

${ }^{20}$ Pierre Ansart, Marx et l'anarchisme. Essai sur les sociologies de Saint-Simon, Proudhon et Marx, PUF, Paris, 1969, pp. 20-43.

21 'L'Industrie n'est qu'un seul et vaste corps dont tous les membres se répondent et sont pour ainsi dire solidaires; le bien et le mal de chaque partie affecte toutes les autres; ce n'est partout qu'un intérêt, qu'un besoin, qu'une vie". Claude Henri de SAInt-Simon, "L'Industrie", en OSSE, vol. XVIII, p. 137. 
la política, a todas luces insuficiente para garantizar la estabilidad social, el imaginario sansimoniano reivindicaría la superioridad de una organización basada en la igualdad y la solidaridad de todos los integrantes:

El objetivo único, al que deben tender todos los pensamientos y esfuerzos, es la organización más favorable de la industria...es decir, un gobierno donde el poder político solo posea la acción y fuerza necesarias para impedir que los trabajos útiles sean perturbados, un gobierno donde todo sea ordenado para que los trabajadores, cuya reunión forme la sociedad verdadera, puedan intercambiar directamente entre sí y con entera libertad el producto de sus diferentes trabajos; un gobierno tal, en suma, en el que la sociedad, la única que puede saber lo que le conviene, lo que quiere y prefiere, sea también el único juez del mérito y la utilidad de los trabajos ${ }^{22}$.

La consideración de industrial concedida a todo individuo "que desempeñara un trabajo de utilidad directa para la sociedad"23 y su inserción en un nuevo sistema económico dominado por necesidades recíprocas y, consiguientemente, por una división del trabajo más compleja, permitió a Saint-Simon presentar a los miembros de la sociedad como actores partícipes de una solidaridad dinámica, integrantes de un único y vasto cuerpo, en lo que cabe calificar de proyecto de homogeneización de la sociedad.

Lógicamente, pese a este optimismo respecto a los mecanismos de redistribución natural del sistema, el pensador francés era consciente de que las crecientes exigencias de la organización industrial, el desarrollo científico y los conocimientos necesarios para la administración reclamaban y justificaban una cierta forma de jerarquía y de división de competencias ${ }^{24}$. Es más, para él establecer relaciones de subordinación y de superioridad entre las capacidades y las fuerzas de ejecución —o lo que es lo mismo, la configuración de una estructura piramidal de la sociedad - constituía la principal garantía para erradicar la arbitrariedad y los antagonismos de los estadios pretéritos de la existencia humana.

22 "Le but unique où doivent tendre toutes les pensées et tous les efforts, c'est l'organisation la plus favorable à l'industrie...c'est-à-dire un gouvernement où le pouvoir politique n'ait d'action et de force que ce qui est nécessaire pour empêcher que les travaux utiles ne soient troublés, un gouvernement où tout soit ordonné pour que les travailleurs dont la réunion forme la société véritable, puissent échanger entre eux directement, et avec une entière liberté les produits de leurs travaux divers; un gouvernement tel, enfin, que la société, qui seule peut savoir ce qui lui convient, ce qu'elle veut et ce qu'elle préfère, soit aussi l'unique juge du mérite et de l'utilité des travaux". Ibid., pp. 165-166 (en cursiva por el autor).

${ }^{23}$ Claude Henri de SAINT-SimOn, "Le parti national ou industriel comparé au parti anti-national", en Le politique, pp. 195-209.

${ }^{24}$ ANSART, Marx et l'anarchisme, p. 32. 
La legitimación de la autoridad corría paralela al creciente descrédito del concepto de dominación política, que el autor indisociablemente vinculaba, sirviéndose de la historia, a la explotación ejercida por el hombre sobre sus congéneres en el pasado y condenada a extinguirse en el futuro:

Este amor por la dominación, que es ciertamente indestructible en el hombre, ha quedado sin embargo anulado en gran parte gracias al progreso de la civilización, o al menos, sus inconvenientes casi han desaparecido en el nuevo sistema. Efectivamente, el desarrollo de la acción sobre la naturaleza ha cambiado la dirección de ese sentimiento trasladándolo hacia las cosas. El deseo de mandar sobre los hombres se ha transformado gradualmente en el deseo de hacer y deshacer la naturaleza a nuestro antojo. A partir de ese momento, el deseo de dominar, innato en todos los hombres, ha dejado de ser dañino, o al menos, se puede divisar la época donde dejará de ser dañino y devendrá útil25.

El papel concedido al Estado y a lo político en la mayor parte de los escritos de Saint-Simon se inscribiría dentro de esa voluntad de establecer un consenso permanente entre individuos dotados de aptitudes y capacidades diferentes, pero comprometidos en un mismo proyecto de creación colectiva ${ }^{26}$. Bajo este enfoque, el principio de una gestión administrativa supondría que los intereses de los productores serían orientados de forma que incrementaran el capital de la colectividad, y recíprocamente, que esta gestión racional contribuyese al mejoramiento del bienestar moral y físico de cada individuo, incluyendo dentro de este las naturales aspiraciones de promoción y ascenso en la escala social.

Todo ello permite afirmar que Saint-Simon deseaba el gobierno de las elites, pero al situar el eje de su superioridad en el ámbito del conocimiento y de la capacidad, estableció una divisoria decisiva con el pensamiento liberal contem-

25 "Cet amour de la domination, qui est certainement indestructible dans l'homme, a été cependant annulé en grande partie par les progrès de la civilisation, ou, au moins, ses inconvénients ont à peu près disparu dans le nouveau système. En effet, le développement de l'action sur la nature a changé la direction de ce sentiment en le transportant sur les choses. Le désir de commander aux hommes s'est transformé peu à peu dans le désir de faire et de défaire la nature à notre gré. De ce moment, le désir de dominer, inné dans tous les hommes, a cessé d'être nuisible, ou au moins, on peut apercevoir l'époque où il cessera d'être nuisible, et où il deviendra utile". SAINT-SimON, "L'Organisateur", en OSSE, vol. XX, pp. 126-127.

${ }^{26}$ Francois Perroux, "Saint-simonisme du XXe siècle et création collective", en Industrie et création collective, T. 1, PUF, Paris, 1964, passim. 
poráneo ${ }^{27}$, que lo haría sobre la propiedad, situando el debate no entre quién tenía y quién no, sino entre quién sabía y quién no.

Al distinguir entre la administración de las cosas y el gobierno de las personas, y que Saint-Simon identificaba como coto de la clase política entonces en el poder, el conde contribuye a poner los cimientos de una nueva era regida por el principio supremo de la organización. Encumbrado a la máxima jerarquía de los fenómenos sociales, tal principio respondía perfectamente a las necesidades de control social - un medio para impartir orden, estructura y regularidad a la sociedad - así como a las aspiraciones naturales del ser humano de profundizar sus rasgos solidarios y afectivos con el resto de sus semejantes.

Tal ha sido el impacto de este planteamiento que algunos autores consideran, no sin razón, que ha impregnado tanto la naturaleza del Estado como la de casi todos los discursos ideológicos de nuestro tiempo y ha contribuido a la "depreciación del carácter político del orden político" 28 , cada vez más limitado al gobierno del mundo externo y material ${ }^{29}$.

\section{SAINT-Simon Y EL PENSAMIENTo Liberal}

El nuevo marco propuesto situaba en un plano secundario la supuesta centralidad de las libertades individuales abstractas y su consagración como principios esenciales de la nueva sociedad, si no definitivamente al menos hasta que no se hubiera alcanzado la indispensable estabilidad social, que solo podía venir como resultado del desarrollo sin trabas y con toda la extensión posible de aquellas capacidades materiales y teóricas, útiles a la acción colectiva:

Porque la verdadera libertad no consiste de ninguna manera en permanecer con los brazos cruzados, si queremos, en la asociación, tal inclinación debe ser reprimida severamente donde quiera que exista; ella constituye lo contrario a desarrollar, sin trabas y en toda su extensión posible, una capacidad temporal o espiritual útil a la asociación ${ }^{30}$.

${ }^{27}$ Un pensamiento representado por aquel entonces por nobles como La Fayette, Victor de Broglie, Le Rochefoucault-Liancourt, $\mathrm{u}$ hombres de generaciones anteriores como Benjamin Constant o Destrutt de Tracy.

${ }^{28}$ Sheldon S. Wolin, Política y perspectiva, Amorrortu, Buenos Aires, 2001, p. 450.

${ }^{29} \mathrm{La}$ reconsideración de estas pautas dominantes en la cultura política contemporánea se encuentra igualmente presente en la obra de Javier RoIz, Sociedad vigilante y mundo judio en la concepción del Estado, Editorial Complutense, Madrid, 2008, passim.

30 "Car la vrai liberté ne consiste point à rester les bras croisés, si l'on veut, dans l'association; un tel penchant doit être réprimé sévèrement partout où il existe; elle consiste au contraire à 
Pese a todo, más allá de estas críticas, lo cierto es que el pensador francés no se encontraba a tanta distancia de sus adversarios liberales. De hecho, al reducir el papel del individuo concreto a la consideración no menos abstracta y genérica de productor, esto es, al convertirlo en una pieza homogénea e indiferenciada más del engranaje productivo de la nueva sociedad industrial, estaba relativizando su individualidad. Solo reconocía la existencia histórica de cada hombre de acuerdo a su naturaleza, ubicación específica y desempeño en su marco de actividad:

En una sociedad organizada en torno al objetivo positivo de trabajar en su prosperidad, el acto político más importante, aquel que consiste en fijar la dirección hacia la cual la sociedad debe marchar, ya no pertenece a los hombres investidos de funciones sociales, es ejercida por el cuerpo social mismo; es de esta manera que la sociedad, concebida colectivamente, puede realmente ejercer la soberanía, soberanía que ya no consiste en una opinión arbitraria elevada a ley por la masa, sino en un principio derivado de la naturaleza misma de las cosas, y de la cual los hombres no hacen sino reconocer su precisión y proclamar su necesidad ${ }^{31}$.

Para Saint-Simon, la Restauración había impedido a Francia, tras la Revolución y el fin del viejo sistema del Antiguo Régimen, avanzar por el buen camino: el tránsito de un sistema teológico y feudal a otro productivo. La instauración de un sistema transitorio había supuesto, en cambio, el dominio de una clase intermedia, integrada por abogados y legistas - una fórmula de equilibrio notable entre la vieja y la nueva clase ociosa - en detrimento de la verdadera clase productiva.

A diferencia del inmovilista marco normativo liberal, Saint-Simon haría descansar los cimientos de su empresa colectiva en los principios vivos y actuantes de asociación y emancipación, más acordes con aquella concepción dinámica y, por qué no, también dialéctica que el maestro, y más tarde sus discípulos, se había ido forjando del proceso de civilización humano.

développer, sans entraves et avec toute l'extension possible, une capacité temporelle ou spirituelle utile à l'association". SAINT-SIMON, "Du Système industrielle", en OSSE, vol. XXI, pp. 15-16.

31 "Dans une société organisée pour le but positif de travailler à sa prospérité, l'acte politique le plus importante, celui qui consiste à fixer la direction dans laquelle la société doit marcher, n'appartient plus aux hommes investis des fonctions sociales, il est exercé par le corps social luimême; c'est de cette manière que la société, prise collectivement, peut réellement exercer la souveraineté, souveraineté qui ne consiste point alors dans une opinion arbitraire érigée en loi par la masse, mais dans un principe dérivé de la nature même des choses, et dont les hommes n'ont fait que reconnaître la justesse et proclamer le nécessité". SAINT-Simon, "L'Organisateur", en OSSE, vol. XX, pp. 197-198. 
Las crecientes trabas a la difusión de su proyecto - algo, sin duda, estrechamente ligado a la progresiva pérdida de apoyo entre los sectores industriales y financieros - llevaron a Saint-Simon a imprimir un brusco giro a su discurso, teñido con el transcurso del tiempo de un mayor grado de voluntarismo. Cada vez haría menos énfasis sobre los aspectos más jerárquicos y autoritarios de la nueva sociedad, e insistiría más en los beneficios derivados del principio de asociación, en especial en aquellos relacionados con la supresión de los privilegios $\mathrm{y}$ de las barreras tradicionales.

Frente a la tendencia seguida por los teóricos liberales, como François Guizot (1787-1874), Augustin Thierry (1795-1856) o Benjamin Constant (17671830), que intentaban unir tanto conceptual como políticamente a las clases medias, cara a la formación de una nueva elite sustentada sobre el talento y la eficacia, Saint-Simon percibió de una manera muy diferente el conflicto. En su opinión, la base de la explotación ejercida por la clase ociosa ya no se localizaba en la esfera económica sino en la política.

Llegados a este punto, puede afirmarse que el discurso sansimoniano deja de constituirse exclusivamente en un proyecto de reorganización social paralelo $\mathrm{y}$, en base a su adscripción industrialista, complementario del liberal, para incorporar una vertiente de crítica política y social. Este salto cualitativo no puede entenderse, desde luego, sin tener en cuenta la extraordinaria carga de moralización adquirida por su proyecto. En efecto, bien podría decirse que Saint-Simon pasa de una fase marcada por su fervor por el progreso a otra donde domina el progreso del fervor. Por supuesto, no iba a ser el único; frente a las crecientes limitaciones mostradas por la metafísica y la ciencia, la moral y la religión — encarnados en el discurso romántico - encontrarían en aquellos primeros años de la Restauración un pleno renacimiento. De cualquier manera, se trataba de una religión que ahora iba a participar de la filosofía del progreso; como él, otros muchos desde Victor Cousin (1792-1867) a Felicité de Lamennais (1782-1854), se sirvieron igualmente de ella como medio para reconstituir el hilo de la historia, interrumpido por la Revolución ${ }^{32}$.

\section{EL MAESTRO Y SU ESCUELA}

Cuando Saint-Simon apele a un nuevo cristianismo, no aspirará a inventar una nueva religión, sino más bien a extraer del viejo los principios de una moral adaptada a la sociedad industrial y de subordinarle el culto y el dogma.

${ }^{32}$ Frank Paul Bowman, "Religion, politics and utopia in French Romanticism": Australian Journal of French Studies, vol. XI (1974), pp. 307-324; del mismo autor, Le Christ des barricades, 17891848, Cerf, Paris, 1987, passim. 
La tonalidad moral y religiosa adquirida ahora por el discurso supondrá una considerable rebaja del optimismo natural expresado antaño por el autor. Las relaciones creadas espontáneamente por la actividad industrial ya no eran consideradas suficientes para mantener la unidad. Los discípulos serán los que constaten en mayor medida la frustración ante la decepcionante deriva adquirida por las ciencias, con su especialización y parcelación creciente, y su consiguiente pérdida de unidad ${ }^{33}$.

Esta evolución acabó desembocando en sus últimos escritos, como el Nouveau Christianisme (1825), en una expresa reivindicación de los intereses y condiciones de existencia de las clases industriales, especialmente los de la más pobre y numerosa ${ }^{34}$, y en la formulación de un código moral en el que destacaban valores como el altruismo, el amor fraterno y el mejoramiento de las condiciones de existencia de la mayoría.

En los últimos años de su vida, Saint-Simon se había ido rodeando de un grupo de colaboradores que, atraídos por sus ideas y proyectos, acabaron participando en las obras postreras del maestro. Ese fue el caso de Olinde Rodrigues (1795-1851), Léon Halèvy (1802-1883) o J. B. Duvergier (1792-1877) ${ }^{35}$. A la muerte del conde, sus discípulos, cada vez más numerosos, muchos de ellos reclutados de la École Polytechnique, decidieron continuar su obra, promoviendo la edición de un diario, Le Producteur: journal philosophique de l'industrie, des sciences, et des beaux-arts. En su publicación participaron algunos de los que serían las principales cabezas del movimiento sansimoniano: Philippe Buchez (1796-1865), Prosper Enfantin (1796-1864), Saint-Amand Bazard (1791-1832) y Paul-Mathieu Laurent (1793-1877). Tras el cierre de la revista, a finales de 1826, hubo que esperar dos años para que el círculo más estrecho de discípulos se dispusiera a exponer y difundir la doctrina del maestro, a partir de una serie de sesiones públicas cuyo contenido fue finalmente recogido en los dos volúmenes de la Exposition de la Doctrine (1828-1830).

Desde fines de 1829, el grupo acabó formando un colegio (Collège) bajo la doble autoridad de Bazard y Enfantin, constituidos en Padres Supremos. El Collège desplegó una ambiciosa labor de evangelización a través del envío de misiones por otras regiones de Francia, así como fuera del país (Bélgica).

\footnotetext{
${ }^{33}$ PICON, Les saint-simoniens, p. 180.

${ }^{34}$ Claude Henri de SaInT-Simon, Nouveau Christianisme, Paris, 1825, p. 57.

${ }^{35}$ Es el caso de Opinions littéraires, philosophiques et industrielles, o Nouveau Christianisme, ambas de 1825 .
} 
Los conflictos dentro del movimiento (básicamente, desavenencias entre Bazard y Enfantin), su quiebra económica y la persecución política sufrida (sus líderes fueron procesados por ultraje a la moral pública) terminarían desembocando en la disolución de la sociedad sansimoniana a finales de 1832. Pese a su dispersión, la mayoría de sus antiguos miembros conservaron buena parte de su ideario y trasladaron muchos de sus planteamientos a proyectos futuros, especialmente en el terreno económico.

Pese a que la escuela se comprometió a conservar intacto el legado del maestro, el cambiante contexto político y social, y la necesidad de expandir el proyecto más allá del círculo de la burguesía industrial y financiera — donde inicialmente surgió - llevaron al sansimonismo a desarrollar y profundizar los aspectos más netamente religiosos y morales, ya perceptibles en el último Saint-Simon. Asimismo, condujo a ampliar su ámbito de difusión a colectivos sociales (trabajadores, mujeres) no contemplados inicialmente por el maestro.

\section{LA CAPACIDAD DEL PODER ESPIRITUAL}

Si Saint-Simon apeló al sentimiento y a la religión fue por muy diversos motivos. La progresiva desconfianza hacia el automatismo y el carácter gradual de los mecanismos de desarrollo económico, el cuestionamiento del mito del papel progresivo de las fuerzas emprendedoras a la vista de la creciente defección en las filas del partido industrialista, o la amplitud de la fractura abierta entre la sociedad real y la sociedad proyectada ocasionaron esa pérdida de fe en la exclusiva capacidad regeneradora de la razón. Todo ello impulsó un profundo reajuste del discurso. Ante las exigencias de una adecuada recomposición ideológica de los equilibrios sociales, el nuevo discurso iba a cimentarse sobre la base de un renovado poder espiritual ${ }^{36}$.

La religión que imaginaría Saint-Simon al final de su vida no constituía tanto la promesa de un futuro lejano como la revelación de la riqueza y posibilidades casi infinitas ofrecidas por el presente, presto a satisfacer todas las aspiraciones humanas cuando los hombres se aplicasen a ello con todas sus fuerzas. Configurada como un principio de participación e integración activo dirigido a despertar y atraer las energías individuales de ese virtual cuerpo de productores, recurrir a ella revela las contradicciones del proyecto sansimoniano. Arrastrado por el erróneo diagnóstico de los males de su sociedad, el proyecto se iba a ver

${ }^{36}$ Mirella LarizzA-Lolli, Scienza, industria e societa: Saint-Simon e i suoi primi seguaci, Il Saggiatore, Milano, 1980, pp. 120ss. 
obligado a responder a las exigencias de reorganización impuestas por la sociedad posrevolucionaria revistiendo su discurso sobre la naturaleza y el sentido de la condición social del hombre de un claro contenido religioso y trascendente ${ }^{37}$.

La moralización de su doctrina, igualmente palpable en otros reformadores de la época como Robert Owen (1771-1858) ${ }^{38}$, le permitía, en efecto, elevarse por encima de los serios escollos reales que impedían la realización de su proyecto de integración social, y trasladar la responsabilidad del clima de división y crisis reinante hacia los entonces rectores de la sociedad francesa.

Mediante este giro táctico, Saint-Simon primero, y sus discípulos después, estos ya dentro de un contexto dominado más por la reconciliación que por el conflicto, buscarían superar su profunda decepción ante las expectativas incumplidas, sin caer en el pesimismo antropológico. Para ello, orientaron su mensaje político a las masas, tradicionalmente excluidas de todo proyecto y devenidas ahora en el nuevo interlocutor ideal. Este cambio de estrategia ponía el acento en el papel de las fuerzas sociales más que en la razón, en tanto motor de la historia, como había venido siendo hasta entonces. Sin embargo, la elección de un nuevo destinatario para su mensaje acabaría repercutiendo muy poderosamente en su propio contenido ${ }^{39}$.

Siendo conscientes del papel esencial de la opinión pública - "la fuerza moral más grande que existe" a las masas, que se movían más por esquemas de conocimiento místico-intuitivos que por los puramente racionales ${ }^{41}$. Se trataba de teñir la labor política de un fuerte colorido ético y, con ello, reactivar la disponibilidad hacia la acción, considerablemente desalentada en los últimos tiempos por las angustias y miserias de la filosofía materialista y racionalista; pero también se buscaba devolver al pp. 111ss

${ }^{37}$ Eugenio del Río, La izquierda. Trayectoria en Europa Occidental, Talasa, Madrid, 1999,

${ }^{38}$ En una línea similar apunta la reciente tesis doctoral de José Ramón ÁlVAREZ LAYNA, De la tradición utópica en Occidente: Robert Owen (Universidad de Alcalá de Henares, 2013).

${ }^{39}$ Cuando la cultura y la propaganda se juntan, la elaboración cultural de las elites se impregna de los esquemas mentales de las capas culturalmente inferiores, desembocando, en ocasiones, en la simplificación formal de los sistemas teóricos, a la disolución de sus marcos lógicos y a la invasión de la afectividad. Georges DuBY, "La vulgarisation des modèles culturels dans la société féodale", en Niveaux de culture et groupes sociaux, Actes du colloque réuni du 7 au 9 mai à l'École normale supérieure, Mouton, Paris-La Haye, 1971, pp. 33-40.

40 "[L]a force morale la plus grande qui existe". SAINT-SimON, "L'Industrie", en OSSE, vol. XIX, p. 91.

${ }^{41}$ Neil Mcwilliam, Dreams of Happiness. Social Art and the French Left. 1830-1850, Princeton University Press, Princeton, 1993, p. 45. 
primer plano de aquella nueva sociedad la religión y el arte, dos catalizadores idóneos para favorecer la concordia y la adhesión social ${ }^{42}$.

A fin de cubrir el vacío angustioso que los regentes políticos no parecían capaces ni dispuestos a llenar, la doctrina aceptó el desafío de descubrirle un sentido y delimitar el curso del porvenir. Sin embargo, acabaron incurriendo en la misma contradicción que la ideología liberal en el poder. Terminaron determinando el establecimiento de una etapa culminante —una época orgánica - que pondría fin definitivo a la condición dialéctica de las series históricas precedentes. Para alcanzar tales objetivos, el sansimonismo recurriría a las fuentes cristianas, especialmente a la escatología y a la Parusía, relativas al final de los tiempos y al advenimiento del reino de Dios, muy familiares y sensiblemente operativas a la hora de aproximarse a las masas.

Al mismo tiempo, al intentar conciliar un mensaje de progreso con el advenimiento de una edad de oro inquebrantable - "la edad de oro del género humano no se encuentra detrás de nosotros, sino delante, en la perfección del orden social"43 el movimiento apuntó ya la que sería una de las ambigüedades fundamentales de la modernidad: la coexistencia de una apología del cambio con el proyecto de marcar el final de las revoluciones sucesivas de la sociedad y la cultura ${ }^{44}$.

\section{LA CONSTRUCCIÓN DE UNA TEOCRACIA}

Más allá de su innegable potencial movilizador, lo cierto es que todo el dinamismo inherente a este proyecto de reorganización social se hacía recaer sobre una estructura jerárquica. Desde su cúspide habrían de partir las directrices y normas de encuadramiento y organización del conjunto de energías desplegadas. En tanto suprema autoridad, este poder espiritual aparecería como el único órgano competente capaz de superar los inevitables procesos de disgregación social intrínsecos a cualquier forma de vida asociada.

Las atribuciones otorgadas al cuerpo de sacerdotes apuntaban a dos tipos de argumentación: la primera, presentaba al sacerdote — un mediador en la relación hombre/dios - como el intérprete más fiel y cualificado de los designios reser-

${ }^{42}$ Mirella LARIZZA-LOLLI, "Socialisme et utopisme: deux catégories à méditer? Quelques considérations à partir du cas du saint-simonisme", en Romantismes et socialismes en Europe 1800-1848, Didier Erudition, Paris, 1988, pp. 137-150.

43 “"[L]'âge d'or du genre humain n'est point derrière nous, il est au devant, il est dans la perfection de l'ordre social". Claude Henri de SAINT-SimON, "De la réorganisation de la société européenne" (1814), en OSSE, vol. XVII, pp. 247-248.

${ }^{44}$ PICON, Les saint-simoniens, p. 63. 
vados por la Providencia a la sociedad; la segunda, por otro lado, partía de la idea de que la conducta humana era de naturaleza emotiva, es decir, irreflexiva e irracional, y por tanto, sus actos eran más el resultado de pasiones trascendentes que de comportamientos racionales. Ambos argumentos, claramente formulados en la Exposition de la Doctrine (1830) por los discípulos, legitimaban el papel central de la figura sacerdotal a la hora de excitar los sentimientos más profundos del hombre y canalizarlos hacia los fines propios de la colectividad.

Férreamente jerarquizada y sometida a un poder religioso que abarcaba todos los aspectos de la existencia, esta sociedad reunía todos los rasgos propios de una teocracia. En efecto, como señala Picon, "la sociedad sansimoniana del futuro no es tecnocrática considerada en su globalidad...no es la competencia técnica (especialista) lo que distingue a sus dirigentes de las otras clases de la sociedad, sino la intensidad con la que ellos son capaces de amar a los hombres y al mundo en el que viven" ${ }^{45}$. Más aun, a la vista de la doble tarea encomendada a los sacerdotes, consistente en coordinar la actividad industrial así como mediar entre la dimensión material y espiritual de la vida humana, quizá resultara más conveniente hablar de una hierocracia.

En cualquier caso, se trataba de una concepción del poder exclusivamente funcional, que respondía a una voluntad deliberada de servirse del auxilio de la divinidad para proyectar una nueva concepción del funcionamiento y de los fines de la vida asociada, que se situara por encima de los métodos tradicionales de diálogo y debate político:

Hasta este momento la sociedad experimenta una necesidad tan viva de dirección para sus sentimientos y sus actos, que acabará por retornar a la Iglesia o la antecámara de los reyes militares, antes que gobernarse a sí misma como entiende el liberalismo...en otras palabras, la sociedad tiene constantemente esa necesidad de fe sin la cual no hay sociedad...La fe es inherente al hombre, es ella la que le convierte en sociable y perfectible y es precisamente porque el hombre disfruta de esta facultad que es necesario confiar su dirección a los hombres más capaces de dirigirla: en esto reside todo el problema de organización política o de constitución del poder ${ }^{46}$.

${ }^{45}$ Ibid., p. 201.

46 "Jusque à ce moment la société éprouve un besoin si vif de direction pour ses sentiments et pour ses actes, qu'elle finirait par retourner a l'Église ou dans l'antichambre des rois militaires, plutôt de se gouverner elle-même comme l'entend le libéralisme...en d'autres termes, la société a constamment ce besoin de foi sans lequel il n'y a pas de société...La foi est inhérente à l'homme, c'est elle qui le rend être sociable et perfectible et c'est précisément parce que l'homme jouit de cette faculté qu'il est nécessaire de confier sa direction aux hommes les plus capables de la diriger: 
Saint-Simon y los sansimonianos no serían, desde luego, los únicos en vacilar en su fe ante la razón. El sentimiento de desamparo dominante que reina a partir de 1830 coincidiría con la instauración de la Monarquía de Julio. Es una etapa de profundas transformaciones que afectarían más al seno social que a la superficie del Estado. Pese al clima de desesperanza, agravado por la grave crisis económica y social, la escuela sansimoniana formaría parte de un amplio grupo de reformadores que, lejos de arrastrarse por el abatimiento y abandonar su proyecto, acabarían adaptándose a los nuevos retos con un nuevo modelo de consenso social, diseñado a partir de la sacralización de los valores y del ideal de sociedad promovido.

La sacralización del trabajo y la jerarquía, o la consideración de la industria y la ciencia como vías ineludibles para la culminación del encuentro definitivo del hombre con Dios, acabaron por contribuir a la creación de un culto panteísta. En efecto, las tesis sobre la sustancia única de Baruch Spinoza (1632-1677) o las del idealismo alemán ${ }^{47}$ terminarían influyendo en la religión sansimoniana. En ella se privilegiaba tanto lo material como lo espiritual y, a la vez, permitía situar bajo la supremacía de una autoridad religiosa dos funciones esenciales para la estabilidad social, como eran la económica y la ideológica, cara a un objetivo último: planificar las energías disponibles, optimizar los recursos humanos y distribuir de forma estricta cometidos y tareas. El resultado serían profesiones de fe como esta de 1833:

\author{
¡Tierra! \\ Ya no eres un valle de lágrimas \\ Tierra fecunda y propicia \\ Tierra de oro y plata \\ Tierra de ágata y pórfido \\ Tierra suave y ligera \\ Tierra de amor y voluptuosidad \\ Tu eres \\ ¡El templo de DIOS!48.
}

\footnotetext{
c'est là tout le problème d'organisation politique ou de constitution du pouvoir". Carta de Prosper Enfantin a su prima (abril, 1829), Bibliothèque de l'Arsenal, Ms 7643, $\mathrm{f}^{\mathrm{o}} 33$.

${ }^{47} \mathrm{La}$ asimilación vino en buena medida por parte del hermano de Olinde Rodrigues, Eugène, traductor de L'Education du Genre Humain de Lessing, pero también indirectamente vía Constant (De la religion, considérée dans sa source, ses formes et ses développements, 1825-1827). Pierre Deguisse, Benjamin Constant méconnu. Le livre de la Religion, Droz, Paris, 1966, passim; Philippe REGNIER, "Les Saint-Simoniens et la philosophie allemande ou la première alliance intellectuelle franco-allemande": Revue de synthèse, IV série, n. ${ }^{\circ} 2$ (abril-junio 1988), pp. 231-245.

48 “Terre! /Tu n'es plus une vallée de larmes /Terre féconde et propice, /Terre d'or et d'argent, /Terre d'agate et de porphyre, /Terre douce et légère, /Terre d'amour et de volupté /Tu es /Le
} 
El sansimonismo se servía de los esquemas religiosos tradicionales para redefinir el concepto de divinidad sobre la base de la exaltación de las nuevas pautas organizativas y materiales —nucleadas en torno a la industria- y sacralizar nuevos valores morales más conformes con la necesaria tarea de emancipación social pendiente $\mathrm{y}$, por tanto, muy alejados del catolicismo — que evocaba la opresión y la iniquidad del pasado- . Teniendo esto en consideración, bien cabe concluir que nos encontramos ante un panteísmo concebido como una religión laica:

La humanidad, pues, tiene un porvenir religioso; la religión del porvenir debe ser la expresión del pensamiento colectivo de la humanidad, la síntesis de todas sus concepciones, la regla de todos los actos. No solo ella está llamada a tomar lugar en el orden político, sino, también, propiamente hablando, la institución política del porvenir, considerada en su conjunto, no debe ser sino una institución religiosa ${ }^{49}$.

\section{A MODO DE BALANCE: EL SANSIMONISMO, ENTRE REALIDAD Y UTOPÍA}

A la hora de analizar la vertiente política del sansimonismo, así como la de cuantos proyectos reformadores surgieron a lo largo del primer tercio del diecinueve, pueden emplearse dos parámetros. El primero, dominante en la mayor parte de estudios, ha instalado su objeto de estudio en el contenido de las doctrinas, circunscribiendo su interés en los límites dogmáticos de los sistemas. En el caso de Saint-Simon, esto ha significado privilegiar, por ejemplo, su interés obsesivo por la organización ${ }^{50}$.

El segundo, menos frecuente pero posiblemente más preciso, buscaría restituir la actualidad de los textos y las prácticas del tiempo insertando su discurso en la realidad política y social de entonces ${ }^{51}$, con lo que ello supone de confrontación, y por tanto de crítica, con respecto a esta.

temple de DIEU! (43-44)". Desessarts, Pensées politiques et religieuses du Saint-Simonien, Paris, 1833, Bibliothèque de l'Arsenal (BA), Ms. 7861, Fonds Enfantin, Brochure IX.

49 "Donc l'humanité a un avenir religieux; la religion de l'avenir doit être l'expression de la pensée collective de l'humanité, la synthèse de toutes ses conceptions, la règle de tous les actes. Non seulement elle est appelée à prendre place dans l'ordre politique, mais encore, à proprement parler, l'institution politique de l'avenir, considérée dans son ensemble, ne doit être qu'une institution religieuse". Doctrine de Saint-Simon, Exposition, Première année, 1829, p. 316.

${ }^{50}$ Paul Benichou, Les temps des prophètes. Doctrines de l'âge romantique, Gallimard, Paris, 1977, p. 259.

${ }^{51}$ Jacques RANCIÈRE, La nuit des prolétaires. Archives du rêve ouvrier, Fayard, Paris, 1981, passim; Miguel Abensour, "L’Utopie socialiste", en Le temps de la réflexion, Gallimard, Paris, 1981, p. 69. 
Ambas perspectivas, no obstante, resultan complementarias. Permiten explicar una misma realidad, la proyectada por unos reformadores que, más allá de sus diferencias, compartían su fuente de inspiración en el fracaso de la Revolución francesa y abrieron un espacio de experimentación radicalmente nuevo. Todos ellos, de una manera u otra, buscaban enlazar el cuerpo social a los hilos del pasado, en función de las leyes naturales y humanas, constantemente invocadas para reconstruir un mundo descompuesto, a la espera de una regeneración próxima $^{52}$.

Sin embargo, desde la perspectiva de autores como Saint-Simon y, sobre todo, sus discípulos, algunas de las disfunciones de su sociedad, a medio camino entre un pasado aparentemente superado y un porvenir aún incierto, fueron percibidas con una especial perspicacia. La misma lógica demostrativa que les había conducido a construir formidables modelos perfectos, les llevaría igualmente a atacar la irracionalidad de su sociedad ${ }^{53}$.

A ese respecto, y ya desde muy pronto, Saint-Simon se emplearía a fondo a la hora de defender la verosimilitud de sus proyectos políticos y sociales y rechazar cualquier posible vinculación con la utopía reafirmando, precisamente, su voluntad de inscribirse en la realidad dictada por la historia y los acontecimientos de su tiempo. El recurso al método positivo constituía el mejor instrumento para acabar con los prejuicios y, sobre todo, arrojar alguna luz sobre los verdaderos obstáculos que entorpecían la libertad humana:

Quien dice utopía dice incertidumbre sobre la posibilidad, o imposibilidad, sentida de una manera vaga, de la ejecución de un nuevo sistema de organización social. Ahora bien, esa vaguedad o incertidumbre, ¿a qué tienden, si no es un poco a la costumbre que tenemos de considerar la gran serie de hechos históricos relati-

${ }^{52}$ Miguel Abensour, Le procès des Maîtres Rêveurs, Editions Sulliver, Arles, 2000, p. 50.

${ }^{53}$ El sentido crítico desplegado por Saint-Simon en los últimos años de su vida no es nuevo, se encuentra inscrito en el pensamiento del autor ya desde sus primeras obras. El foco de sus análisis continúa siendo la pervivencia de los residuos del Antiguo Régimen y la necesidad de articular un proyecto de sociedad industrial. En este sentido, la defensa a ultranza de su nueva sociedad y su crítica política se encuentran indisolublemente unidas en el autor. En la medida en que el curso de los acontecimientos y la dinámica histórica dominante en la Francia de mediados del siglo diecinueve apuntan a un modelo político, social y económico más complejo —e igualmente más alejado del inicialmente previsto por el conde- el discurso crítico de este y, sobre todo, de sus discípulos, cobra pujanza y profundidad. Las líneas maestras de la doctrina se mantienen e, incluso, se ven reafirmadas, pero la exigencia de una mayor visibilidad y presencia en un escenario social y político poblado de actores y colectivos emergentes (mujeres, obreros) redimensionará su condición crítica a fin de poner en cuestión las insuficiencias del sistema vigente. 
vos a la marcha de la civilización, o por decirlo mejor, a la ignorancia completa que la educación nos deja normalmente a este respecto? Si estuviéramos tan familiarizados con esta serie de observaciones a la que estamos poco [acostumbrados], juzgaríamos casi súbitamente si, en un vistazo, tal perfeccionamiento propuesto es practicable, o bien si no lo es, y en ese caso, por qué motivo. En todo caso, la idea de utopía desaparecería porque no significa ninguna otra cosa que nuestra incertidumbre relativa sobre aquellas tres categorías a la cual debe corresponder el proyecto dado ${ }^{54}$.

La comprensión del presente pasaba por reintegrar el momento particular en el desenvolvimiento histórico y por aislar las dinámicas fundamentales. En consecuencia, solo era posible concebir la política desde una óptica pluridimensional, que en el caso de Saint-Simon estaba marcada por su vocación científica de partida. Este enfoque era capaz de conciliar una neta predisposición por el establecimiento de vastos sistemas altamente organizados con un profundo espíritu crítico hacia la realidad social, que estaba muy lejos de ser la mejor de las posibles. Solo así, posiblemente, pueda captarse el sentido de una declaración de intenciones tan sumamente extensiva como la recogida en la Exposition de la Doctrine:

Para nosotros el sistema político abarca el orden social entero: comprende la determinación del objeto de actividad de la sociedad, la de los esfuerzos necesarios para alcanzarlo; la dirección a dar a esos esfuerzos, ya sea en su división, ya sea en su combinación; el reglamento de todos los actos colectivos o individuales; y finalmente el de todas las relaciones de los hombres entre sí, desde las más generales hasta las más particulares ${ }^{55}$.

54 "Qui dit utopie dit incertitude de la possibilité, ou impossibilité, sentie d'une manière vague, de l'exécution d'un nouveau système d'organisation sociale. Or, ce vague et cette incertitu de, à quoi tiennent-ils, si ce n'est au peu d'habitude que nous avons de considérer la grande série des faits historiques relatifs à la marche de la civilisation, ou, pour mieux dire, à l'ignorance complète ou l'éducation nous laisse d'ordinaire à cet égard? Si nous étions aussi familiarisés avec cette série d'observations que nous le sommes peu, nous jugerions presque subitement si, en aperçu, tel perfectionnement proposé est praticable, ou bien s'il ne l'est pas, et, dans ce denier cas, par quel motif...Dans tous les cas, l'idée d'utopie disparaîtrait parce qu'elle ne signifie rien autre chose que notre incertitude relativement à celle de ces trois catégories à laquelle doit correspondre le projet donné". SAINT-Simon, "L'Organisateur", en OSSE, vol. XX, pp. 63-64.

55 "Pour nous le système politique embrasse l'ordre social tout entier: il comprend la détermination du but d'activité de la société, celle des efforts nécessaires pour l'atteindre; la direction à donner à ces efforts, soit dans leur division, soit dans leur combinaison; le règlement de tous les actes collectifs ou individuels; celui enfin de toutes les relations des hommes entre eux, depuis le plus générales jusqu'aux plus particulières". Doctrine de Saint-Simon, Exposition, Première année, 1829, p. 123. 
Lógicamente, la irrupción del discurso sansimoniano en el escenario político francés, marcado por la crisis de la Restauración, como hemos mencionado anteriormente, supuso una fuerte conmoción, especialmente en el campo liberal. Las fuertes críticas lanzadas desde publicaciones como Le Producteur generaron una gran controversia. Los periódicos más significados (Journal du Commerce, Le Constitutionnel o Le Globe) arremetieron contra su extremado dogmatismo. Los sansimonianos, hasta hacía bien poco en el bando opuesto, fueron acusados de buscar sofocar la autonomía del individuo, tanto en el terreno material —en aras a la lógica de los intereses de la industria - como en el intelectual y moral - sometido a un poder omnipotente, inaccesible para los asociados ${ }^{56}$.

No obstante, el debate abierto por el sansimonismo no desbordó los cauces habituales de la prensa y los círculos intelectuales ${ }^{57}$. El movimiento era contemplado como una tentativa más, entre otras, que pretendía ser aquella ideología integradora capaz de convertirse en el cemento del nuevo orden ${ }^{58}$. Habría que esperar a noviembre de 1831, a raíz de la revuelta de los tejedores de la ciudad de Lyon, para que la doctrina sansimoniana volviera a reclamar la atención. En efecto, desde los círculos oficiales no se tardó en responsabilizar a la misión evangelizadora desarrollada en aquella ciudad unos meses atrás. Sus directrices dejaban claramente patente la inscripción activa y crítica de la escuela en la compleja realidad de su tiempo. Sirvan de ejemplo estas palabras de Enfantin dirigidas a los responsables de la misión del Midi:

${ }^{56}$ Entre los autores más beligerantes, Benjamin Constant en su discurso en el Ateneo, el 3 de diciembre de 1825, luego publicado bajo el título: "Coup-d'oeil sur la tendance générale des esprits dans la dix-neuvième siècle": Revue encyclopédique, Paris, XXVIII, nº 84 (diciembre 1825), pp. 663-674; Paul BASTID, "Benjamin Constant et le saint-simonisme": Économies et Sociétés, t. IV, 6 (1970), pp. 1149-1153; STENDHAL, D'un nouveau complot contre les industriel (1825) y Fernand RUDE, "Stendhal et les saint-simoniens": Économies et Sociétés, t. IV, 6 (1970), pp. 1121-1147. Las bases de la crítica liberal del sansimonismo serían recogidas durante la II Guerra Mundial y la posterior Guerra Fría por una serie de autores liberales, que aprovecharon este bagaje teórico para situar allí las bases teóricas de los regímenes totalitarios (entre ellos Karl Popper, Jacob Talmon, Hannah Arendt, Friedrich Hayek, Georg G. Iggers, etc.).

${ }^{57}$ El discurso político del sansimonismo también levantó duras reacciones en el seno de la llamada escuela teológico-feudal que reprochaba al nuevo movimiento algo ya avanzado desde el bando liberal: su voluntad de envilecer la espiritualidad del hombre hacia un árido productivismo.

${ }^{58}$ Una tentativa frustrada pues — como señala F.-A. Isambert - la nueva generación "tenía todavía que definir sus posiciones en el universo intelectual de sus predecesores". François-André ISAMBERT, De La Charbonnerie au saint-simonisme, Étude sur la jeunesse de Buchez, Les Éditions de Minuit, Paris, 1966, p. 63; Alan B. SPITZER. The French Generation of 1820, Princeton University Press, Princeton, 1987, p. 274. 
Haced historia, haced política, retomad el primer volumen de la "Exposición", inspiraros en su lectura, comentadla, traducidla, ponedla al nivel de todas las inteligencias, pero ante todo, tratad de despertar las simpatías. Que esta clase más numerosa y más pobre, que esas mujeres que tanto nos necesitan, a las que nosotros mismos también necesitamos y que no nos piden Kant o Hegel, Cousin ni Platón sino más bien una religión nueva, se encuentren ante vosotros con sus miserias, sus dolores, sus vicios, su ignorancia, cuando llevéis nuestra palabra ${ }^{59}$.

Dado que entre los círculos políticos oficiales no se encontraban motivos concretos, más allá de la miseria, para explicar la escalada de conflictividad social, el objetivo consistió en situar la responsabilidad en los propagadores de ideas subversivas que incitaban a las masas a la agitación. Para la alta burguesía y la clase política surgida de la Monarquía de Julio, el choque de clases no podía ser más que fortuito, ligado a las impaciencias y a la incapacidad de comprender los límites de la modernidad engendrados por la Revolución. Los proletarios, como si de menores de edad se tratara, serían la encarnación de esa impaciencia infantil que les impedía percibir los innegables avances obtenidos que solo paso a paso, y a través de una sólida y progresiva formación - $-\mathrm{y}$, añadimos, sumisión y resignación-, podrían verse culminados satisfactoriamente.

Sería entonces cuando, a través de Louis Reybaud (1799-1879), con sus artículos publicados entre 1836 y $1838^{60}$ y más tarde, Alfred Sudre (1820-1902), con su Histoire du communisme ou réfutation historique des utopies socialistes, editada en un año tan decisivo como 1848, se asistiría al despliegue de una formidable campaña de descalificación ideológica. Su objetivo sería confinar el sansimonismo y otros movimientos altamente heterogéneos dentro de una coherencia común: la que dictaba la condición utópica de unos proyectos de regeneración quiméricos e irrealizables que, pese a sus buenos deseos - reconocidos por todos estos críticos de manera paternalista - estaban condenados a chocar y romperse una y otra vez contra la realidad de los hechos.

59 'Faites de l'histoire, faites de la politique, reprenez le premier volume de 'l'Exposition', inspirez-vous de sa lecture, commentez-le, traduisez-le, mettez-le au niveau de toutes les intelligences; mais avant tout, cherchez à éveiller les sympathies. Que cette classe la plus nombreuse et la plus pauvre, que ces femmes qui ont tant besoin de nous, dont nous avons tant besoin nous-mêmes et qui ne nous demandent pas Kant ou Hegel, Cousin ou Platon mais bien une religion nouvelle, soient toujours devant vous avec leurs misères, leurs douleurs, leurs vices, leur ignorance, lorsque vous portez notre parole". Julio, 1831, Bibliothèque de l'Arsenal; Fonds Enfantin Ms 7620, fo 94; Fernand RUDE, L'insurrection lyonnaise de novembre 1831, Le mouvement ouvrier à Lyon de 1827 à 1832, Editions Anthropos, Paris, 1969, passim.

60 "Les socialistes modernes; les saint-simoniens, Fourier et Owen", luego incluidos en su obra central Études sur les réformateurs ou socialistes modernes (1840-1843). 
Estos textos fueron difundidos tan ampliamente que son ellos y no Karl Marx (1818-1883), los que contribuyeron a acuñar el término socialismo utópico para aludir a las doctrinas de Saint-Simon, Charles Fourier (1772-1837) y Owen $^{61}$. En ellos se recurría al relato histórico para mostrar la escasa capacidad de innovación de estos reformadores y asociarlos a la larga cadena de sonados fracasos que, desde el albor de los tiempos — desde Platón y Esparta - habían tratado de refundar los patrones de organización social, y finalmente no habían supuesto más que una rémora al proceso de civilización y progreso de la humanidad. Pero si se sirvieron de la historia para evacuar del presente aquellos proyectos que consideraban ilusorios e irrealizables, condenándolos a la condición de utopías, fue por una motivación en absoluto velada:

En tanto esas excursiones intelectuales permanezcan en el terreno de la teoría, pueden ejercitar útilmente el espíritu filosófico del que se desprende progresivamente, lo que ellas portan en sí mismas de ideas sanas y practicables; pero cuando ellas se traducen, sin preparación, en hechos positivos; cuando ellas se manifiestan bruscamente mediante temerarias tentativas de realización, el peligro deviene inminente: los vínculos sociales se relajan, las creencias saludables se extinguen en la duda; el desprecio hacia la tradición conduce al desprecio de todo principio moral, el presente se desata violentamente del pasado, y se precipita hacia un porvenir pleno de amenazas ${ }^{62}$.

${ }^{61}$ Existen varias tesis sobre el contacto de Marx con el pensamiento sansimoniano. Algunos lo asocian a las lecturas de este de la obra de Karl Grun, Die soziale Bewegung in Frankreich und Belgien: Briefe und Studien (Darmstadt, 1845) —El movimiento social en Francia y en Bélgica-, ya que en la cuarta parte de La ideología alemana (1845-1846) Marx critica a Grun la influencia del sansimonismo en la formación del socialismo científico. En cualquier caso, fuera como fuese, esta obra sí permitió a Marx familiarizarse con el término socialismo utópico que Grun había utilizado en su obra influido por los libros de Reybaud, Louis Blanc (Histoire de dix ans 1830-1840, Paris, 1841) y Lorenz Von Stein (Der Sozialismus und Kommunismus des heutigen Frankreichs, Leizpig, 1842). Todo parece indicar que Marx, que supo distinguir entre la obra de Saint-Simon y la de sus discípulos, conoció la obra de estos a través de los escritos de Ludwig Gall y los miembros de la Société du Casino de Treveris, a través de su futuro suegro Ludwig von Westphalen, y muy especialmente a través de los jóvenes hegelianos Eduard Gans y Moses Hess.

62 "Tant que ces excursions intellectuelles restent à l'état de théorie, elles peuvent exercer utilement l'esprit philosophique qui en dégage, par degrés, ce qu'elles portent en elles d'idées saines et praticables; mais lorsqu'elles se traduisent, sans préparation en faits positifs; lorsqu'elles se manifestent brusquement par de téméraires tentatives de réalisation, le danger devient imminent. Les liens sociaux se relâchent, les croyances salutaires s'éteignent dans le doute; le mépris de la tradition amène le mépris de tout principe moral; le présent se détache violemment du passé, et se précipite vers un avenir plein de menaces". Antoine JAY, "Rapport présenté a l'Académie française le 20 avril 1841", en Louis Reybaud, Études sur les réformateurs ou Socialistes Modernes. Saint-Simon, Ch. Fourier, R. Owen, Paris, 4ª ed., 1844, t. I., p. VI; RIOT-SARCEY, Le réel de l'utopie, p. 250. 
A diferencia de la crítica marxista — que al tomar constancia, al menos inicialmente, de la historicidad profunda de las doctrinas sansimonianas, tomó la medida de su poder de interpelación crítica y política ${ }^{63}$ - esta firme voluntad por parte del bando hegemónico liberal de refutar, mediante su invalidación, el discurso de Saint-Simon y sus discípulos, no hizo sino confirmar la extremada inscripción de su mensaje político en la sociedad de su tiempo. Su condición utópi$\mathrm{ca}$, en otras palabras, no derivaba tanto de su desacuerdo con la realidad en la cual se producía como de su potencial capacidad de transgresión del orden social dado y ya existente que por todos los medios la burguesía en el poder deseaba preservar.

\section{¿UN LEGAdO PARA EL MUNDO DE HOY?}

Más allá de los apreciables errores detectados tanto en sus diagnósticos como en sus proyectos de organización social, el sansimonismo constituyó un eje de reflexión política determinante en la sociedad de su tiempo. Una reflexión consciente de la magnitud de las transformaciones en curso así como de los obstáculos a los que se enfrentaban; testimoniando, en suma, la gran complejidad de una sociedad industrial en pleno proceso de implantación, con las luces y sombras propias de un periodo sumido en la fe en el progreso y el miedo a la incertidumbre.

El amplio arco de sus preocupaciones - muchas de ellas compartidas por sus contemporáneos, aunque posiblemente no desde un enfoque de tan alto vuelo- llevó a Saint-Simon y a sus discípulos a formular ambiciosas propuestas. Persiguieron moldear la sociedad a partir de una concepción de la política apegada a la ciencia pero no menos respetuosa de la vertiente interrelacional que aspiraba a dominar los comportamientos humanos. Sin embargo, la gestión administrativa $\mathrm{o}$, en todo caso, tecnocrática no bastaba para lograr sus propósitos.

${ }^{63}$ Si Marx reconoció (Manifiesto Comunista,1848), pese a todo ello, la contribución de este socialismo crítico-utópico al desarrollo de un discurso crítico radical de la sociedad, acorde con las necesidades del proletariado, más tarde Engels (en su Del Socialismo utópico al socialismo científico,1880) se mostraría más intransigente al reforzar la oposición entre ciencia y utopía. Esta intensificación de la crítica marxista con respecto a estas doctrinas, no debe separarse, sin embargo, de la creciente doctrinarización que la ciencia marxista va a sufrir a fines del siglo diecinueve y que culminaría más tarde con el marxismo-leninismo. Henri MALER, "Socialisme utopique", en Michèle Riot-Sarcey, Thomas Bouchet y Antoine Picon (eds.), Dictionnaire des Utopies, Larousse, Paris, 2002, pp. 205-208; Arthur E. BESTOR Jr., "The Evolution of the Socialist Vocabulary": Journal of the History of Ideas, vol. 3, n. 9 (1948), pp. 259-302; Peyton V. Lyon, "Saint-Simon and the Origins of Scientism and Historicism": The Canadian Journal of Economics and Political Science, vol. 27, n. 1 (1961), pp. 55-63. 
La exaltación de la actividad productiva y la lucha contra el parasitismo, la apología de la industria y de su papel progresivo, la valorización de las capacidades y la batalla contra todo igualitarismo nivelador, la insistencia sobre la necesidad de una organización científica de la obra de transformación de la naturaleza, la fe en el papel emancipador del trabajo y en sus potencialidades regeneradoras y, sobre todo, el reconocimiento de la explotación industrial del mundo como fin supremo en torno al cual orientar la creatividad humana y la organización de la vida social ${ }^{64}$ constituían cuestiones que excedían el papel asignado al sistema que habían concebido, ya fuera sobre bases racionales, como lo fue en un principio, o sobre cimientos religiosos y morales, como lo fue al final.

Pese a todo, el sansimonismo abrió nuevas vías, fruto en buena parte de su arduo esfuerzo por aprehender los engranajes que hacían funcionar la sociedad. A la vista de los cambios vertiginosos experimentados en su tiempo, sus miembros pudieron comprobar la validez y el error de sus diagnósticos y los de muchos de sus contemporáneos, que habían pronosticado un horizonte de progreso y bienestar infinito para todos sus conciudadanos.

Al mostrar las insuficiencias del presente y lo inverosímil del futuro proyectado, los sansimonianos también contribuyeron a labrar una tradición crítica. Esta tradición, sin ser en absoluto original, sí puede considerarse decisiva para comprender los intensos debates que las sociedades industriales contemporáneas todavía hoy se siguen planteando, en ningún caso utópicamente.

${ }^{64}$ LARIZZA-Lolli, Scienza, industria e societa, pp. $105 \mathrm{ss}$. 